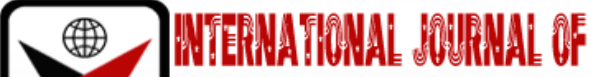 MNOWATE: RFEARCH 6 DEVEOPMENT
}

ISSN 2278-0211 (Online)

\section{Perception on Language of Instruction in Primary Schools on Form Two National Assessment in Public Secondary Schools in Moshi Municipality, Tanzania}

Theobald Michael Mushi
Student, Department of Education Management, Planning \& Financing and Life Long
Learning, Mwenge Catholic University, Tanzania
Malusu J M.
Associate Professor Department of Education Management,
Mwenge Catholic University, Tanzania
Dr. Catherine Muteti
Senior Lecturer, Department of Education Management,
Mwenge Catholic University, Tanzania

\begin{abstract}
:
Learning is a process that is best facilitated through language of instruction. Mastering language of instruction can influence academic performance. Education system recognizes the use of both Kiswahili and English as medium of instruction in primary and secondary schools. Kiswahili is used for normal public primary schools and English is used for private English medium primary schools. Eventually, both students are required to learn in English as they join secondary schools. Does the shift from Kiswahili to English affect students' academic performance in secondary schools? This paper sought to assess perceptions on language of instruction in primary school on Form Two National assessment in public secondary schools in Moshi Municipality in Tanzania. Ex post facto design was used. Questionnaires were used to collect quantitative data. The study found that students whose language of instruction in primary was Kiswahili exhibit positive mobility in secondary school where as students whose medium of instruction was English in primary school showed negative mobility.
\end{abstract}

Keywords: Language of instruction, student academic performance, public secondary school

\section{Introduction}

Learning is a process that is best facilitated through language of instruction, which is well understood by learners (Brock-Utne et al, 2010). Linguistically, language is acknowledged as the vehicle in which cultural norms and traditions are carried through from generation to generation (Batibo, 1995). So language of instruction does the same in education that means knowledge is passed from teacher to student via language of instruction in a particular community. In Tanzania pupils enrolled in primary schools have different background of the language other than the language of instruction in schools. At the Primary school level, most pupils come to school with linguistic background of their vernacular language. A few pupils who are in urban areas use Kiswahili as their first language. According to Education act 37 of the year 1961 Kiswahili was declared as a language of instruction in primary school in Tanzania. English language was retained for instruction in secondary education and tertiary education (Petzell, 2012). Before the year 1995 there were few international curriculum based schools in Tanzania, which served the children of foreigners and foreign diplomats working in the country (Rubagumya, 2010). Thus, the education system categorizes curriculum in primary school into two systems.

One system is English Medium primary schools and another system is Kiswahili Medium primary school. Kiswahili is used as language of instruction in normal primary schools and English language is used in Secondary schools. Pupils have to shift from Kiswahili Language of instruction in normal primary schools into English language in secondary schools. Students who attend English Medium primary schools continue with the same language of instruction in secondary schools. So the shift from Kiswahili to English seems to affect students' academic performance in secondary schools. According to Tanzania Institute of Education (2014), good number of students who complete primary education in normal primary schools lack mastery of English language due to the fact that English as subject in primary schools is not taught communicatively and competently which in turn, affect students' academic performance in secondary schools.

Evidence shows that secondary schools teachers are complaining the inability of students to follow the lessons taught in English in form one and form two. For instance, students in secondary schools cannot read textbooks written in English and prepare their own notes. Furthermore, when are given subject notes by teachers they end up copying words 
by words. If there is a spelling mistake they cannot correct it (Adamson, 2020). Also students in secondary schools discuss their assignments in Kiswahili and write in English. Group discussion in done in Kiswahili during preparation and write their examinations in English. Mixing the language in learning process seems to affects the students' performance in secondary schools (Martine, 2018; Lupogo, 2014). Therefore students may fail or score low marks in their examinations due to lack of English language Skills.

However, Telli (2014) noted that English language in Tanzania is Language of instruction protected by status quo. For instance, Adamson (2020) and Benson (2016) observed that the reasons to select and use foreign language for instructions in the educational system were belief and culture. Belief entails that learning by using the foreign language, which serves, as global lingua franca is a way to master the language. Also it provides chance for the graduates to participate in the global economy. On the other hand the use of foreign language is the colonial legacy that perpetuates the linguistic and culture imperialism to the developing world (Adamson, 2020; Saad et al., 2014; Batibo, 1995).

Nevertheless, when compared the trend in primary school survival rates of the year 2019, the survival rates in primary schools is higher by $7 \%$ than the ordinary secondary level survival rates. Also the 2019 ordinary secondary level survival rates show a decline trend. The analysis of grade-to-grade promotion showed high level of repetition and drop out at form two (Education Sector Performance Report, 2019). So, it seems that in primary schools where the majority of schools engage Kiswahili as language of instruction the survival rate is higher while in lower secondary schools where language of instruction is English the survival rates is lower. It seems the use of foreign language might be the hindrances that contribute to the decline in survival rates. Importantly, Moshi municipality has 52 primary schools where by 35 belongs to government and 17 are non-government primary schools. The $32 \%$ percent of primary school in Moshi Municipality are English medium (ESPR, 2019). This might have influence Form Two National Assessment in Moshi Municipality. Form Two National Assessment Moshi Municipality position was 18 in the year 2017 and 13 the year 2018 (BEST, 2018). The academic performance in form two results of the two systems differs substantially as shown in Table 1.

Table 1: provides summary of Form Two National Results 2018, 2019 and 2020 in Moshi Municipality. Data indicated percentage of students who scored Division I-III; Division IV and referred. This shows the performance trend for the mentioned years.

\begin{tabular}{|c|c|c|c|}
\hline Division & $\mathbf{2 0 1 8}$ & $\mathbf{2 0 1 9}$ & $\mathbf{2 0 2 0}$ \\
\hline I-III & $57 \%$ & $54 \%$ & $57 \%$ \\
\hline IV & $37 \%$ & $41 \%$ & $40 \%$ \\
\hline Referred & $6 \%$ & $5 \%$ & $3 \%$ \\
\hline
\end{tabular}

Table 1: Performance Summary of FTNA Results 2018 in Moshi Municipality

Source: (MSEO 2021)

Arguably, society has different perceptions about where to send their children. Some parents feel that their children might do better if they educate them in English medium primary schools than in public primary school. Out of simple survey, researcher noted that many elite parents seem to send their children in English medium primary school. Probably they believe that pupil will do better than students who learn in Kiswahili. So this study investigated perception on language of instruction in primary school on Form Two National Assessment in public Secondary schools.

\section{Literature Review}

\subsection{Language of Instruction and Students Academic Performance}

Studies have been conducted by different scholars to provide explanation on the relationship between the languages of instruction and the academic success of students. Civan and Coskun (2016) conducted a study to investigate the effect of instruction in students' non-native language on the academic success of University students in Turkish University using semi natural experiment in which data of students from nine departments were used. Employing the students' semester average point (SPAs) between 2005 and 2010 as the unit of analysis the study found that instruction in the non-native language affects negatively the academic success of students. The findings seem to affirm that native language is the best for instruction in schools.

Similarly Agirdag and Vanlaar (2016) conducted a study that focuses on better understanding of how students' language background and use are related to academic achievement in Belgium. The study used cross-section design in which questionnaires were used to collect students' information on language background and use. Multivariate three level analyses were conducted on 5,000 schools and 120,000 students in 18 countries across Europe and Asia. The study found that there was an achievement gap between language minority and native speakers.

Komba and Bosco (2015) conducted a study to investigate the influence of students' background in the language of instruction on secondary school academic performance in Tanzania. The study employed cross-sectional design under quantitative research approach, in which information of form one student from 8 schools which were randomly selected were reviewed. Examination result for 524 students in which 262 were Swahili medium students and the other 262 English Medium students were analyzed. The findings showed that students, whose medium of instruction at primary school level was English, performed better in form one annual examination than their counterparts who used Kiswahili and the difference was statistically significant in a two-tailed test. The Findings were similar to findings by Mlay (2010) conducted study to investigate influence of the language of instruction on students' academic performance in secondary school contrasting urban and rural secondary schools in Tanzania. 
The study by Cekiso et al. (2015) investigated the role of English language Proficiency as a predictor of academic achievement among primary English First additional language learners' in South Africa. The study used correlation research design. The sample of the study was purposeful chosen in which 215 grade 8 students were involved in which 108 were male and 107 were female of age 15 and 18. The study revealed that there was no relationship between learners' English proficiency and their academic performance in Mathematics, Economics and Management Science. The findings were contrary the findings by Kisumbe and Mashala (2020) who conducted a study on the effect of the language of instruction on learning in secondary Education in Dodoma. The study was quantitative in which dependent t-test for paired sample was used. A purposive sample of 288 students was used in the study. The study found that English Language inhibit the understanding of the subject and limits the room for active involvement in learning.

Maalim (2017) conducted a study on students' underachievement in English medium subjects in Zanzibar employing semi natural experiment design. A sample of 54 form two students participated in the study. Biology study was taught in Kiswahili and it was assessed in Kiswahili; then same subject was taught in English and assessed in English. The findings revealed that students performed far better when the subject was taught and assessed in Kiswahili compared to when the same subject was taught and assessed in English. The findings are contrary to the status quo assumption that English language can best be learned when used as the language of instruction (Tell, 2014).

The literature reviewed shows some variations in their findings. Civan and Coskun (2016) found that instruction in the non-native language affects negatively the academic success of students in Turkish Universities. Komba and Bosco (2015) found that students, whose medium of instruction at primary school level was English, performed, better in form one annual examinations than their counterparts who used Kiswahili and the difference was statistically significant in a two-tailed test. Cekiso et al (2015) found that there was no relationship between learners' English proficiency and their academic performance in Mathematics, Economics and Management Science in South Africa. The studies have not shown influence of shifting from one language of instruction to another on academic performance. This study filled the gap by research on the perception on language of instruction in Primary school on Form Two National Assessment in Public Secondary schools in Moshi Municipality.

\section{Research Question}

What influence prior knowledge of language of instruction in primary school has on Form Two National Assessment in public secondary schools in Moshi Municipality?

\section{Hypothesis}

There is significant difference between the mean score perception of students from English Medium Primary and students from Kiswahili Medium Primary on the effects of prior knowledge of language of instruction on Form Two National Assessment in Public secondary schools.

\section{Theoretical Framework}

The study was guided by Theory of Language Policy proposed by Spolosky in 2004. The theory described three components: practice, beliefs and management. Language practices are the observable behavior and choices. What people actually do. This can be speaking the language in restricted area such as learning institutions. Also it may be used everywhere in daily social activities (Spolosky, 2018). The second component is beliefs about language. The beliefs that are most significant are the values assigned to the variety and features. The values may be my nation, my education class, my region or my ethnic heritage. These values are used for identity of an individual. Benson (2016) found that the values assigned to language contributed much in the selection of language of instructions in the Developing countries. According to Spolosky (2018) the third component is language management, which is the observable effort by an individual or an institution with authority to develop directive on issues concerning language. This component is critical because it determines who uses the language when to use it, where to use it and how the language may be used. Spolosky pointed out that the most obvious form of language management is a constitution, language policy document or a law established by a nation-state. For example, the language policy may require using a specific language as medium of instruction in Education.

According to Albury (2016) the factors in theory of language by Spolosky are the driving force to Language Policy. Similarly these components were discussed in Language Management Theory (LMT) (Jernudd and Neustupny, 1980).The practical link of these theories to developing Nations in Africa. According to Mwaniki (2011) Language Management Theory in the context of Africa is to prioritize African domestic languages. This allows the full engagement of indigenous knowledge system. It calls for a shift from external world to internal world, from foreign to the local one. In this way the African standpoint might better contribute to Africa much needed capacity.

\section{Methodology}

The study used Ex post facto design. This design was used because the researcher intended to use quantitative data from Form Two National Assessment 2020 results and see if there is relationship to the effect of prior knowledge of language of instruction in primary schools. Similar design has been use in the study by Sehic, (2017) and Abah, (2018) Questionnaires were used to collect quantitative data from 258 form three students, 72 teachers in public secondary Schools. Interview schedule was used to collect data from 6 Heads of Public secondary schools and 1 Moshi Municipal Education Officer. The returned instruments were 253 questionnaires for students, 64 questionnaires for teachers and 6 interview schedules from Head of Schools. Data were coded and analyzed by aid of IBM SPSS (Statistical package for Social Science) version 21. 


\section{Findings}

The objective of the study is to find out the perception on language of instruction in primary schools on Form Two National Assessment. It specifically addresses the effect of language use on student's academic performance in public secondary schools in Moshi Municipality. To accomplish this question, the study employed means scores technique of which two tailed tests are carried out.

Table 2: presents the responses from students who attended Kiswahili medium primary schools and shifted to English language of instruction in secondary schools. The likert scale five point was used Strongly Agree (SA=5 points), Agree $(A=4$ points), Undecided ( $U=3$ points), Disagree $(D=2$ points) and Strongly Disagree ( $S D=1$ point). The question sought to capture the perception of students on effect of prior language of instruction in primary on Form Two National Assessment in public secondary schools in Moshi Municipality.

\begin{tabular}{|c|c|c|c|c|c|c|c|c|c|c|c|}
\hline Test Items & f & SA & $\mathbf{f}$ & $\mathbf{A}$ & $\mathbf{f}$ & $\mathbf{U}$ & $\mathbf{f}$ & $\mathbf{D}$ & $\mathbf{f}$ & $\mathbf{S D}$ & Mean \\
\hline & & $\mathbf{0}$ & & $\mathbf{\%}$ & & $\mathbf{\%}$ & & $\mathbf{\%}$ & & $\mathbf{\%}$ & \\
\hline A & 10 & 5.7 & 95 & 54.7 & 18 & 10.3 & 26 & 14.9 & 25 & 14.4 & 3.2 \\
\hline B & 66 & 37.9 & 71 & 40.8 & 13 & 7.5 & 20 & 11.5 & 4 & 2.3 & 4.0 \\
\hline C & 54 & 31 & 90 & 51.7 & 13 & 7.5 & 11 & 6.4 & 6 & 3.4 & 4.0 \\
\hline D & 30 & 17.2 & 57 & 32.8 & 28 & 16.1 & 49 & 28.2 & 10 & 5.7 & 3.2 \\
\hline E & 90 & 51.7 & 71 & 40.8 & 4 & 2.3 & 5 & 2.9 & 4 & 2.3 & 4.3 \\
\hline F & 17 & 9.8 & 33 & 19.0 & 13 & 7.5 & 54 & 31.0 & 57 & 32.7 & 2.4 \\
\hline G & 15 & 8.6 & 18 & 10.3 & 18 & 10.3 & 64 & 36.8 & 59 & 34 & 3.7 \\
\hline H & 11 & 6.3 & 33 & 19.0 & 8 & 4.6 & 70 & 40.2 & 52 & 29.9 & 3.6 \\
\hline I & 42 & 24.1 & 44 & 25.3 & 14 & 8.0 & 57 & 32.8 & 17 & 9.8 & 3.2 \\
\hline J & 13 & 7.5 & 12 & 6.9 & 4 & 2.3 & 34 & 19.5 & 111 & 63.8 & 1.7 \\
\hline
\end{tabular}

Table 2: Kiswahili Medium Primary Schools, Language of Instruction and Students Academic Performance in Public Secondary Schools

Key: A: I score higher marks in examination because I know English B: I am comfortable learning by using English C: I understand the lesson when teacher uses Kiswahili D: I understand any book written in English when I read alone E: My ability to speak English has increased since I joined secondary school F: I score low marks in my exams because we use English G: I am not comfortable learning by using English H: I do not understand books written in English when I read alone I:I would prefer learning by using Kiswahili rather than English J: My ability to speak English has dropped since I joined secondary school

The findings show that $60.3 \%$ of the students perceived to have scored higher marks because of knowing a language of instruction while $29.4 \%$ disagreed with this display. Students perceive that competence in language of instruction is key to good performance. The findings are supported by linguistic view that language is the vehicle in which cultural norms and traditions are carried through from generation to generation (Batibo, 1995). Hence, language of instruction in secondary schools should be one that is widely used and clear to students and teachers so that can enhance students' academic performance.

Furthermore, the finding reveals that that $78.7 \%$ were comfortably learning in English. These findings revealed that despite the shift of language of instruction from primary school into English in secondary school; students from normal primary schools were comfortable learning in English. The results corresponded with findings by Cekiso et al. (2015) students view English language proficiency as a predictor of academic achievement in South Africa.

Also $82.7 \%$ of the respondents voted to understand the lesson well when a teacher uses Kiswahili language. These findings document a fact that student understood the lesson well when teacher used Kiswahili. The findings were in consonance with the findings by Maalim (2017) that found that students performed far better when the subject was taught and assessed in Kiswahili compared to when the same subject was taught and assessed in English. This is evidence that Kiswahili language can be used as a medium of instruction that in turn, can foster student's performance in secondary schools.

However $50 \%$ of respondents agreed to understand books written in English where as $34 \%$ disagreed. This is evidence that majority of students from Kiswahili medium were able to read and understands books written in English when they read alone. However, 34\% could not read and understand books written in English. Form two Examination questions were written in English. Thus, student who could not read books written in English could not as well understood the questions written in English. Such findings were evidence that shift from Kiswahili into English instruction affect Form Two National Assessment students' academic performance.

The result revealed $92.5 \%$ of the respondents' ability to speak English had increased since joined secondary school. The findings elicited that student from Kiswahili Medium primary schools gain positive mobility in English language competence. This was similar response by teachers and head of secondary schools when asked students from Kiswahili Medium primary school improve their performance as year goes. The findings revealed that as time passed students ability to express in English increases which means at the beginning learning was difficult. The results were in line with the study by Kembo (2020) in Kenya Secondary Schools who found that improvement in reading grammar; writing and vocabulary spill over into the performance of other subjects. Therefore, according to the findings more practice on the language of instruction lead to improvement in student academic performance. 
The findings revealed $29 \%$ of the respondents' linked score of low marks in examinations with the use of English Language where as $64 \%$ disagreed. The findings revealed that majority of students from Kiswahili medium were not affected by the shift from Kiswahili into English language of instruction but $29 \%$ were affected. The students affected are those who score division four in Form Two National Assessment. The same observation was vivid in the Form Two National Assessment results in 2020 where majority scored last grade division IV. The result were supported by Lupogo (2014) revealed that English as language of instruction act as a setback in learning process in Tanzania secondary school and tertiary education.

The findings revealed that $25 \%$ of the respondents did not understand books written in English when read alone where as 70\% understood. Majority of students were not affected by shift from Kiswahili into English language of instruction. However, $25 \%$ were affected that means efforts are needed to help them cope with the change of the language of instruction.

Results showed 49.4\% preferred learning in Kiswahili rather than English. This indicated that English is imposed to students had they have the alternative they would not study by using English language. Adamson (2020) revealed that language of instruction is characterized by important connection between a range of different language values and education related capabilities.

The findings indicated that $83.3 \%$ of the respondents' ability to speak English did not drop since joined secondary school. That means students who shifted from Kiswahili to English language of instruction gain the language proficiency gradually as the year goes.

Table 3 shows the responses of students who attended English medium primary schools. The students did not change language of instruction rather maintained English language of instruction in secondary schools. The likert scale five point was used Strongly Agree ( $\mathrm{SA}=5$ points), Agree ( $\mathrm{A}=4$ points), Undecided ( $\mathrm{U}=3$ points), Disagree ( $\mathrm{D}=2$ points) and Strongly Disagree (SD= 1 point). The question sought to capture the perception of students on effect of prior language of instruction in primary on Form Two National Assessment in public secondary schools in Moshi Municipality.

\begin{tabular}{|c|c|c|c|c|c|c|c|c|c|c|c|}
\hline Test Items & F & SA & $\mathbf{f}$ & $\mathbf{A}$ & $\mathbf{f}$ & $\mathbf{U}$ & $\mathbf{f}$ & $\mathbf{D}$ & $\mathbf{f}$ & SD & Mean \\
\hline & & $\mathbf{\%}$ & & $\mathbf{\%}$ & & $\mathbf{\%}$ & & $\mathbf{\%}$ & & $\mathbf{\%}$ & \\
\hline A & 12 & 15.2 & 51 & 64.6 & 8 & 10.1 & 2 & 2.5 & 6 & 7.6 & 3.8 \\
\hline B & 39 & 49.4 & 38 & 48.1 & 2 & 2.5 & - & - & - & - & 4.5 \\
\hline C & 6 & 7.6 & 42 & 53.2 & 6 & 7.6 & 23 & 29.1 & 2 & 2.5 & 3.4 \\
\hline D & 29 & 36.7 & 34 & 43.0 & 2 & 2.5 & 8 & 10.1 & 6 & 7.6 & 3.9 \\
\hline E & 42 & 53.2 & 16 & 20.3 & 2 & 2.5 & 9 & 11.4 & 10 & 12.7 & 3.9 \\
\hline F & 12 & 15.2 & 10 & 12.7 & 4 & 5.1 & 30 & 38.0 & 23 & 29.1 & 2.5 \\
\hline G & 4 & 5.1 & 2 & 2.5 & 6 & 7.6 & 24 & 30.4 & 43 & 54.4 & 4.3 \\
\hline H & 2 & 2.5 & 2 & 2.5 & 2 & 2.5 & 45 & 57.0 & 28 & 35.4 & 4.2 \\
\hline I & 12 & 15.2 & 28 & 35.4 & 4 & 5.1 & 17 & 21.5 & 18 & 22.8 & 3 \\
\hline J & 13 & 16.5 & 13 & 16.5 & 8 & 10.1 & 18 & 22.8 & 40 & 50.6 & 2.2 \\
\hline
\end{tabular}

Table 3: English Medium Primary, Language of Instruction and Students' Academic Performance in Public Secondary Schools

Source: Field Survey (2021)

Key: A: I score higher marks in examination because i know English B: I am comfortable learning by using English C: I understand the lesson when teacher uses Kiswahili D: I understand any book written in English when i read alone E: My ability to speak English has increased since i joined secondary school F: I score low marks in my exams because we use English G: I am not comfortable learning by using English H: I do not understand books written in English when I read alone I: I would prefer learning by using Kiswahili rather than English J: My ability to speak English has dropped since I joined secondary school

The respondents from English Medium had the following response. The study revealed that 79.8\% respondents scored high marks in examination because they knew English where as $10.1 \%$ disagree. Students perceived that competence in language of instruction is key to good performance. The findings were similar to perception of the student who attended Kiswahili medium primary. Therefore, clear language of instruction is key to students' academic performance in secondary schools in Moshi Municipality.

The findings indicated that $60.8 \%$ of the respondents understood lesson when Kiswahili was used where as $31.6 \%$ did not understand. The study revealed that majority of students from English medium understood lessons when teacher used Kiswahili. The findings were similar to response of students who attended Kiswahili Primary school. This means both groups enjoy and understood lesson in Kiswahili. So Kiswahili which is the language wide used in the community can be used to provide instructions in Public Secondary schools in Moshi Municipality. However 31.6\% disagree with the statement is an indication that student perceive Kiswahili not appropriate for teaching in secondary schools.

Students from English Medium responses revealed that $92.4 \%$ understood English books when read alone where as $5 \%$ did not understand. The findings were similar to responses of students who attended Kiswahili medium primary schools in which 70\% understood books written in English when read alone. However it is clear that the number of students from English Medium primary who understood books written in English is greater than number of students from Kiswahili Medium primary. This indicated that prior knowledge of language of instruction in primary school influence 
students' understanding of books written in English, which enhance students' academic performance in Public Secondary schools.

The findings revealed that majority of the students $50.6 \%$ prefer to learn in Kiswahili rather than in English. This is a policy issue whereas the authority responsible should allow learning to take place in the language which is clear to student and widely spoken in their environment. To alleviate the effect caused by shift from Kiswahili to English language of Instruction. Mwanik (2011) argued that language Management in the African context should prioritize the local languages to engage indigenous knowledge system. It calls for a shift from external world to internal world, from foreign to the local one.

\section{Hypothesis Testing}

In this study two-tailed test was used to test the null hypothesis. The mean score from the responses of students who attended Kiswahili Medium and students who attended English medium primary schools were compared to check for the difference in mean score perception of the students on the influence of the prior knowledge of the language of instruction in primary school on Form Two National assessment students' academic performance in Moshi Municipality.

- H1: states that there in significant difference between the mean score perception of students from English Medium Primary and students from Kiswahili Medium Primary on the effects of prior knowledge of language of instruction on Form Two National Assessment students' academic performance in Public secondary schools.

- Ho: states that there is no significant difference between the mean score perception of students from English Medium Primary and students from Kiswahili Medium Primary on the effects of prior knowledge of language of instruction on Form Two National Assessment students' academic performance in Public secondary schools was rejected.

\section{Significance Level (Alpha Level)}

The significance level is the pre-determined alpha level which is the cut off that the researcher uses to decide when to reject and to fail to reject the null hypothesis. In the study selected Alpha level was 0.05 at which the hypothesis was tested.

\subsection{Assumption for T-test}

- The two groups are independent

- The independent variable is categorical with two groups

- Subject within each group are independently and randomly sampled

\subsection{Decision Rule}

- If the p-value is greater than the pre-determined alpha value then do not reject the null hypothesis

- If the p-value is less than the predetermined alpha value then reject the null hypothesis Table 4: indicates inferential findings on the view of students on Effect of prior knowledge on language of instruction in primary schools on student academic performance in Form Two National Assessment

\begin{tabular}{|c|c|c|c|c|c|c|}
\hline Group & $\mathbf{N}$ & Mean & Std. Dev & T & Df & Sig \\
\hline EM Primary & 79 & 3.7684 & .47381 & 3.079 & 251 & 0.002 \\
\hline KM Primary & 174 & 3.5586 & .51432 & & & \\
\hline
\end{tabular}

Table 4: Summary of Sample Test for Mean

\section{Interpretation of the Results}

This study is guided by a null hypotheses that $(\mathrm{Ho})$ that there is no significant difference between the mean score perception of students from English Medium Primary and students from Kiswahili Medium Primary on the effects of prior knowledge of language of instruction on Form Two National Assessment students' academic performance in Public secondary schools was rejected. The finding shown on Table 4 reveals that $\mathrm{P}$ value is 0.002 , which is less than predetermined alpha value of 0.05 and thus, rejected the null hypothesis. In other words the alternative hypothesis H1: which states that there is significant difference between the mean score perception of students from English Medium Primary and students from Kiswahili Medium Primary on the effects of prior knowledge of language of instruction on Form Two National Assessment students' academic performance in Public secondary schools. This implied the results were statistically significant and that there was significant difference between the mean. This calls for stakeholders to take the appropriate measures such as design a program to facilitate smooth shift from Kiswahili in primary schools to English instruction in secondary schools.

Results from Document analysis generated the following information from Form two national assessment results 2020 in the public secondary schools in Moshi municipality. 


\begin{tabular}{|c|c|c|c|c|}
\hline Measure & \multicolumn{2}{|c|}{ English Medium } & \multicolumn{2}{c|}{ Kiswahili Medium } \\
\hline Division & f & \% & 49 & f \\
\hline I & 18 & 22.8 & 30 & 28.2 \\
\hline II & 27 & 34.2 & 43 & 17.2 \\
\hline III & 32 & 40.5 & 52 & 24.7 \\
\hline IV & 2 & 2.5 & 174 & 29.9 \\
\hline TOTAL & 79 & 100.00 & 100.00 \\
\hline
\end{tabular}

Table 5: Findings on Performance Summary Form Two National Assessment Results 2020

Source: Researcher's Computation 2021

The document analyzed was the score sheets for the form Two National Assessment 2020 results. The results in Table 4: indicates that all group had students who score division I to division IV. However students from Kiswahili Medium primary schools were the majority who scored division IV. The same group had $34 \%$ of students who said could not read and understand books written in English. Form two Examination questions were written in English. Thus student who could not read books written in English could not as well understood the questions written in English. Such findings were evidence that such students scored division IV. This indicates that prior knowledge of the language of instruction in primary schools had effect on Form Two National Assessment students' academic performance in public secondary schools.

Table 6: shows the responses of teachers. The Likert scale five points was used Strongly Agree (SA=5 points), Agree $(A=4$ points), Undecided ( $U=3$ points), Disagree $(D=2$ points) and Strongly Disagree (SD= 1 point).The question sought to capture the perception of teachers on effect of prior language of instruction in primary on Form Two National Assessment in public secondary schools in Moshi Municipality.

\begin{tabular}{|c|c|c|c|c|c|c|c|c|c|c|c|}
\hline Test Items & $\mathbf{f}$ & $\mathbf{S A}$ & $\mathbf{f}$ & $\mathbf{A}$ & $\mathbf{f}$ & $\mathbf{U}$ & $\mathbf{f}$ & $\mathbf{D}$ & $\mathbf{f}$ & $\mathbf{S D}$ & Mean \\
\hline & & $\mathbf{\%}$ & & $\mathbf{\%}$ & & $\mathbf{\%}$ & & $\mathbf{\%}$ & & $\mathbf{\%}$ & \\
\hline 1 & 20 & 31.3 & 31 & 48.4 & 1 & 1.6 & 10 & 15.6 & 2 & 3.1 & 3.9 \\
\hline 2 & 11 & 17.2 & 24 & 37.5 & 4 & 6.3 & 17 & 26.6 & 8 & 12.5 & 3.2 \\
\hline 3 & 4 & 6.3 & 14 & 21.9 & 2 & 3.1 & 28 & 43.8 & 16 & 25.0 & 2.4 \\
\hline 4 & 9 & 14.1 & 23 & 35.9 & 2 & 3.1 & 20 & 31.3 & 10 & 15.6 & 3.0 \\
\hline 5 & 14 & 21.9 & 29 & 45.3 & 1 & 1.6 & 11 & 17.2 & 9 & 14.1 & 3.4 \\
\hline 6 & 3 & 4.7 & 8 & 12.5 & 8 & 12.5 & 15 & 23.4 & 18 & 28.1 & 2.6 \\
\hline 7 & - & - & 16 & 25.0 & 2 & 3.1 & 30 & 46.9 & 16 & 25.0 & 2.3 \\
\hline 8 & 12 & 18.8 & 30 & 46.9 & 3 & 4.7 & 13 & 20.3 & 6 & 9.4 & 3.5 \\
\hline 9 & 20 & 31.3 & 35 & 54.7 & - & - & 2 & 3.1 & 7 & 10.9 & 3.9 \\
\hline 10 & 18 & 28.1 & 13 & 20.3 & 4 & 6.3 & 16 & 25 & 13 & 20.3 & 3.1 \\
\hline
\end{tabular}

Table 6: Teachers Perception on Influence of Prior Language of Instruction in Primary School on Students' Academic Performance in Public Secondary School

Source: Field Survey (2021)

1. Students from EM participate well in class when I am teaching 2. Students from EM score high marks in my subjects 3. Students from KM do not follow lessons in English 4. Students from EM understand my subject when they read alone than students from KM 5. The LoI in primary schools contribute to students' performance in secondary school 6. Students from KM participate less in class 7. Students from KM score low marks in my subject 8.Students from EM slowdown in performance as the year goes 9. Students from KM primary school improve their performance as year goes 10. It is not good for pupils to learn in Kiswahili in primary school then shift to English in Secondary schools

According to the findings 67.2\%agreed with the view that the Language of Instruction in primary schools contributes to students' performance in secondary schools. This was in consonance with the study by Komba\&Bosco, 2015; Adamson, 2020.This is evidence that the language of instruction should be considered an important factor that can influence the academic performance of students.

The findings indicated 65.7\% agreed with the view Students from English Medium slowdown in performance as the year goes. The study found that the students from English Medium slow down as year goes. Student did better in form one and form two but in other classes the form three and form four students from English Medium did not make difference compared to student from Kiswahili Medium.

According to the findings $62.6 \%$ of teachers agreed with the view Students from Kiswahili Medium primary school improve their performance as year goes. These justify that students who shift from Kiswahili to English language of instruction performed poor in form one even in form two. Gradual improved even surpassed students who attended English Medium primary schools. The results were in line with the study by Kembo, (2020) in Kenya Secondary Schools who found that improvement in reading grammar; writing and vocabulary spill over into the performance of other subjects.

According to the findings $48.4 \%$ perceive that it is not good for pupils to learn in Kiswahili in primary school then shift to English in Secondary schools. The findings proved that teachers believed that English language is best for instructions in secondary schools. Mwanik, (2011) argued that language Management in the African context should 
prioritize the local language to engage indigenous knowledge system. It calls for a shift from external world to internal world, from foreign to the local one.

\section{Conclusions and Recommendations}

The study concluded that majority teachers showed English language is the most preferred language of instruction in secondary schools. However, majority of the students prefer to learn in Kiswahili rather than in English. The study found that students whose language of instruction in primary was Kiswahili exhibit positive mobility in secondary school where as students whose medium of instruction was English in primary school showed negative mobility.

\section{Recommendations}

First, the authority responsible should be clear about the language of instruction in secondary school to resolve the contention whether English or Kiswahili. Second, Government should have a clear program to help smooth shift from Kiswahili to English instruction in secondary schools. This can take place at the last two years in primary schools in standard six and seven. Student should have intensive training on English, which will be taught communicatively so as to improve the English language skills.

\section{References}

i. Abah, J. (2018). Academic outcomes in language-dependent and computation-dependent courses among mathematics education students in a Nigerian university: Top-achievers still best of both extremes. Journal of Education \& Social Sciences, 6(2), 64-81.

ii. Adamson, L. (2020). Negotiating Language and Learning: An ethnographic study of students' experiences in two Tanzanian secondary schools (Doctoral dissertation, UCL (University College London)).

iii. Agirdag, O., \&Vanlaar, G. (2016). A hot piece of PISA: The relation between language use and academic achievement. In Cultural Diversity, Migration, and Education conference, Date: 2016/07/07-2016/07/09, Location: Potsdam, Germany (Vol. 485).

iv. iv. Albury, N.J. (2016) National language policy theory: exploring Spolsky's model in the case of Iceland. Lang Policy.https://doi.org/10.1007/s10993-015-9357-z

v. Batibo, H. M. (1995). The growth of Kiswahili as language of education and administration in Tanzania. Contributions to the Sociology of Language, 69, 57-57.

vi. Benson, C. (2016). Addressing language of instruction issues in education: Recommendations for documenting progress. In Background paper prepared for the 2016 Global Education Monitoring Report.

vii. Brock-Utne, B., Desai, Z., Qorro, M. A., \& Pitman, A. (2010). Language of instruction in Tanzania and South AfricaHighlights from a project.BRILL.

viii. Cekiso, M., Tshotsho, B., \& Masha, R. (2015).English language proficiency as a predictor of Academic Achievement among primary English first Additional Language Learners in South Africa. International Journal of Educational Sciences, 9(3), 325-333.

ix. Civan, A., \&Coşkun, A. (2016).The effect of the medium of instruction language on the academic success of University Students. Educational Sciences: Theory \& Practice, 16(6).

x. x. Jernudd, Björn\& J.V. Neustupný. (1987). Language planning: for whom? In Lorne Laforge (ed.), Proceedings of the International Colloquium on Language Planning, 69-84. Québec: LesPresses de L'Université Laval.

xi. Kembo, J. (2020). Using Supervised Extensive Reading (SER) for Improving English as a Language of Instruction (LoI) and Learning: An Exploratory Study based on Observational Evidence.

xii. Kisumbe, L. A., \&Mashala, Y. L. (2020). Effects of the language of instruction on Learning in Secondary Education and Its Implications in Workforce Preparation: A Case of Dodoma, Tanzania. Journal of Public Administration and Governance, 10(3), 215227-215227.

xiii. Komba, S. C., \&Bosco, S. (2015). Do Students' Backgrounds in the language of instruction Influence Secondary School Academic Performance?

xiv. Lupogo, I. (2014). Language of Instruction: A Challenge for Secondary Schools and Tertiary Institutions in Implementing VET in Tanzania. Journal of Educational Policy and Entrepreneurial Research, 1(3), 26-30.

xv. Maalim, H. A. (2017). Students' underachievement in English-medium subjects: The case of secondary school in Zanzibar. Southern African Linguistics and Applied Language Studies, 35(1), 53-62.

xvi. Martine, D. M. (2018). An Assessment of Code Switching to Students' English language Proficiency in Tanzania. A Case of Muleba District (Doctoral dissertation, The Open University of Tanzania).

xvii. Mlay, N. (2010). The influence of the language of instruction on students' academic performance in secondary schools: a comparative study of urban and rural schools in Arusha-Tanzania (Master's thesis).

xviii. Mwaniki, M. (2011). Language management in Africa: The dialectics of theory and practice. Southern African Linguistics and Applied Language Studies 29(3). 243-257.

xix. Ministryof Education Science and Technology, (2019). Education Sector Performance Report (2018/2019) Tanzania Mainland.

xx. Ministry of Education and Culture Tanzania (2014). Education and Training Policy. Retrieved from: http://webcache.googleusercontent.com/search?q=cache:

http://www.tanzania.go.tz/egov_uploads/documents/education_and_Training_Policy_sw.pdf

xxi. Ministryof Education Science and Technology, (2018). Basic Education Statistics

xxii. Petzell, M. (2012).The Linguistic Situation in Tanzania. Modernaspråk, 106(1), 136-144. 
xxiii. Rubagumya, C. M. (2010). English-Medium Primary Schools in Tanzania: A New 'Linguistic Market' In Education?. In Language of Instruction in Tanzania and South Africa-Highlights from a Project (pp. 43-59).Brill Sense.

xxiv. Sa'ad, T. U., \&Usman, R. (2014).The causes of poor performance in English language among senior secondary school students in Dutse Metropolis of Jigawa State, Nigeria. IOSR Journal of Research \& Method in Education, 4(5), 41-47.

xxv. Sehic, S. (2017). College-level second language courses and creative thinking skills: an ex post facto study. The Journal of Language Learning and Teaching, 7(1), 119-142.

xxvi. xxvi.Spolsky, B. A, (2018) Modified and Enriched Theory of Language Policy (and management). Lang Policy 18, 323-338 (2019).https://doi.org/10.1007/s10993-018-9489-z

xxvii. Spolsky, B. (2004). Towards a theory of language policy. Working Papers in Educational Linguistics (WPEL), 22(1), 1.

xxviii. Telli, G. (2014). The Language of Instruction Issue in Tanzania: Pertinent Determining factors and Perceptions of Education Stakeholders. Journal of Languages and Culture, 5(1), 9-16.

xxix. Tanzania Institute of Education (2014).A Guide for the Implementation of Base line Program for Secondary Schools in Tanzania Mainland. 